\title{
Comparative spectroscopic studies on liposomes containing chlorophyll $a$ and chlorophyllide $a$
}

\author{
Sanja M. Milenkovic ${ }^{1}$, Marcela E. Bărbînță-Pătraşcu², Gabriel Baranga², Dejan Z. Markovic ${ }^{1}$ \\ and Laura Ţugulea ${ }^{2}$ \\ ${ }^{1}$ Faculty of Technology, University of Niš, 16000 Leskovac, Serbia \\ ${ }^{2}$ Faculty of Physics, University of Bucharest, 077125 Măgurele, Romania
}

\begin{abstract}
Chlorophyll a (Chla) and chlorophyllide a (Chlida) - a derivative of Chla, have been incorporated in the lipid bilayers of two types of liposomes, small unilamellar vesicles (SUV) and multilamelar vesicles (MLV). The objective of the present work was to compare the spectral behaviour of Chla and Chlid $a$ incorporated in the lipid bilayers and their sensing behaviour at molecular level. The VIS absorption and fluorescence emission presented differences depending on the type of liposomes and inserted pigment, reflecting the different localization of porphyrin macrocycle in the lipid moieties. The temperature dependence of emission anisotropy and fluorescence intensity, for both Chla and Chlid $a$ incorporated in DPPC SUV, revealed the presence of different lipid phases. The degree of incorporation of quercetin (QCT) in liposome membrane was studied by using Chla and Chlid $a$ as molecular sensors. The fluorescence polarisation data and the fluorescence quenching process provided arguments for the insertion of the QCT at the interface lipid/water, in the vicinity of lipid polar heads and porphyrin macrocycle. The phytyl chain of Chla penetrating in the hydrophobic core of the lipid bilayers is responsible for the observed differences among Chla and Chlid $a$ in sensing the lipid phase transition and the fluorescence quenching process induced by QCT.
\end{abstract}

Key words: Chl $a-$ Chlid $a-$ Fluorescence - Liposomes - Quercetin

\begin{abstract}
Abbreviations: Chla, chlorophyll a; Chlid $a$, chlorophyllide a; DMPC, dimyristoylphosphatidylcholine; DMSO, dimethyl sulfoxide; DPPC, dipalmitoylphosphatidylcholine; MLV, multilamellar vesicles; O.D., optical density, PBS, phosphate buffer solution; PDT, photodynamic therapy; QCT, quercetin; SUV, small unilamellar vesicles; VIS, visible light.
\end{abstract}

\section{Introduction}

Chlorophylls and chlorophyll derivatives present very intense and characteristic absorption and fluorescence emission in blue and red part of visible (VIS) light spectrum. The absorption as well as the emission spectra suffer significant changes in biological surroundings, due to their aggregation and/or interaction with lipids, proteins or other present biomolecules. The shifts of more than $20 \mathrm{~nm}$ of the positions of the absorption maximum, as well as of fluorescence

Correspondence to: Laura Țugulea, Faculty of Physics, University of Bucharest, 405 Atomiştilor Street, Măgurele, jud. Ilfov, Romania, 077125

E-mail: laura.tugulea@g.unibuc.ro maximum are not uncommon, making the spectral data obtained in organic solvents of small biological relevance (Moser 1998). The pigments may serve as probes or sensors to monitor different molecular interactions, therefore representing a potential tool for numerous biotechnological applications.

Chlorophylls are abundantly present in light-harvesting complexes of photosynthetic apparatus of plants and green algae (Scheer 2006) where they interact with specific proteins inside thylakoids lipoprotein matrix. The chlorophylls have been also employed as the so-called $2^{\text {nd }}$ and $3^{\text {rd }}$ generation of photosensitizers in photodynamic therapy (PDT) (Rosenbach-Belkin et al. 1998; Brandis et al. 2006a, 2006b); that is why spectroscopic studies of porphyrin-protein complexes, especially those including various derivatives of chlorophylls 
and bacteriochlorophylls as chromophores, have recently attracted a lot of attention (Schlichter et al. 2000; Proll et al. 2006; Markovic et al. 2007).

Chlorophyllide $a$ (Chlid $a)$, a derivative of chlorophyll $a(\mathrm{Chl} a)$, is formed in the last steps of Chla biosynthesis, by reduction of protochlorophyllide $a$ (Scheer 2003a, 2003b; Rudiger 2006) or in degradation processes, like senescence of leaves (Brown et al. 1991), during the normal turnover of pigment-protein complexes (Almela et al. 2000; Yasuyo and Yuzo 2003). The degradation process includes loss of phytyl tail and modification of the side chains of the isocyclic ring of chlorophyll in reactions catalyzed by several enzymes (Yuzo et al. 1996).

Unlike the protochlorophyllide with fully unsaturated porphyrin macrocycle, which is characterized by an intense absorption in the blue spectral region from 400 to $450 \mathrm{~nm}$ (Soret or B-band, $\varepsilon \approx 150000 \mathrm{M}^{-1} \cdot \mathrm{cm}^{-1}$ ) and only a moderate absorption in the red spectral region around $620 \mathrm{~nm}\left(\varepsilon \approx 20000 \mathrm{M}^{-1} \cdot \mathrm{cm}^{-1}\right)$, Chlid $a$ has a phytochlorin system characterized by the absorption bands around 440 and $660 \mathrm{~nm}$ (in organic solvents) of almost equal intensities $\left(\varepsilon \approx 100000 \mathrm{M}^{-1} \cdot \mathrm{cm}^{-1}\right)$ with a conspicuous gap in the green spectral region (Scheer 2006). The $\varepsilon$ values (90689 $\mathrm{M}^{-1} \cdot \mathrm{cm}^{-1}$ at $433 \mathrm{~nm}$ and $78300 \mathrm{M}^{-1} \cdot \mathrm{cm}^{-1}$ at $\left.664 \mathrm{~nm}\right)$, obtained from spectra of Chlid $a$ in $90 \%$ acetone, have been recently reported (Müller et al. 2011). Since the phytyl tail - the main structural factor that differentiate Chla and Chlid $a$ (Figure 1) - has very negligible absorption contribution, compared to the chlorine structure, the absorption maximum positions of the two pigments are very close (662 and $664 \mathrm{~nm}$, in acetone for the "diagnostic" or "red" $\mathrm{Q}_{\mathrm{y}}$ band of Chl $a$ and Chlid $a$, respectively) and $\varepsilon_{\max }$ values are practically the same. The fluorescence maximum positions are also very close, 666 and $667 \mathrm{~nm}$ (in acetone) for Chla and Chlid $a$, respectively (Jeffrey 1997).

The liposomes with Chla are excellent models for biomembranes, specifically for photosynthetic membranes, and were successfully used to study the influence of different agents on the lipid bilayer at molecular level (T,ugulea and Paşcanu 1996). Quercetin (QCT), a representative of a larger flavone family (3, 3',4',5,7-pentahydroxyflavone), is well known for its antioxidant properties (Cvetković et al. 2011; Zvezdanović et al. 2012). It is known that the flavonoid molecule localizes either in the hydrophobic region or in the polar region of the lipid bilayers, depending on hydrogen bonding of the hydroxyl groups (Košinova et al. 2012). Chla has been already used as molecular sensor for revealing specific influence of QCT on liposomes membranes (Drăguşin et al. 2010). The antioxidant properties of QCT haven't been particularly monitored in this study, but important factors contributing to the antioxidant capacity of QCT in the liposome lipid bilayer, like distribution and degree of incorporation, have been considered.

The principal goal of this work was to compare the spectral behaviour (visible absorption and fluorescence) of Chl $a$ and Chlid $a$ incorporated in the lipid bilayers of two different types of liposomes, small unilamellar vesicles (SUV) and much larger multilamelar vesicles (MLV). The spectral bands (both VIS absorption and fluorescence emission) presented differences depending on the type of liposomes and inserted pigment, reflecting the different
Chlorophyll

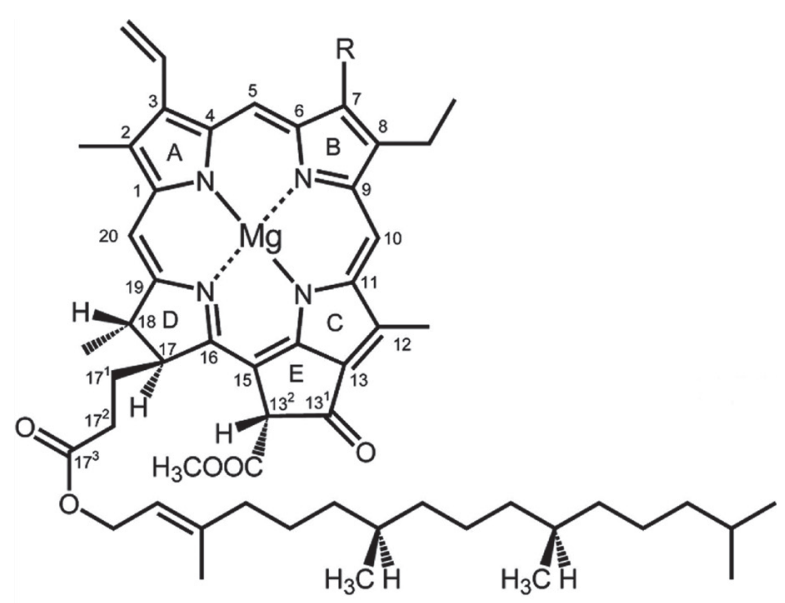

Chlorophyllide

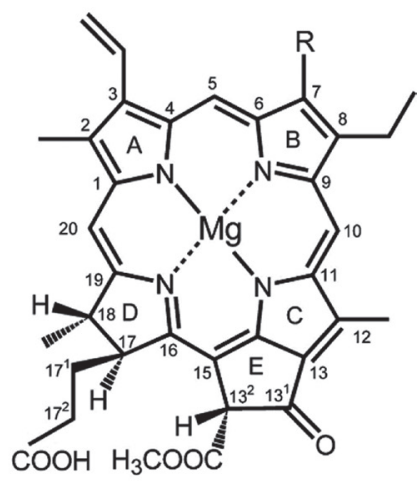

Figure 1. Structure od chlorophyll and chlorophyllide. The C-atoms are numerated according to IUPAC nomenclature rules. In position C-7, - R corresponding to: $-\mathrm{CH}_{3}$ and $-\mathrm{CHO}$ in the cases of Chl $a$ and $\mathrm{Chl} b$, and Chlid $a$ and Chlid $b$, respectively. 
localization of the chromophore (porphyrin macrocycle) in the lipid moities.

The second goal was to compare the effects of QCT on liposome membrane by using Chl $a$ and Chlid $a$ as molecular sensors. Both fluorescence polarisation data and the dynamics of the quenching process provided deeper insight regarding the quercetin localization in the lipid membrane, as well as the degree of rigidity/fluidity of its environment.

\section{Materials and Methods}

\section{Materials and reagents}

Dipalmitoyl phosphatidylcholine (DPPC, critical temperature $\mathrm{T}_{\mathrm{c}}=41.4-41.7^{\circ} \mathrm{C}$ ) was purchased from Sigma Aldrich (Germany) and used without further purification. The phosphate buffer solution (PBS) $\left(\mathrm{NaH}_{2} \mathrm{PO}_{4}-\mathrm{K}_{2} \mathrm{HPO}_{4}\right)$, $\mathrm{pH}=7.4$, was prepared using analytical grade reagents and purified water from a Millipore Milli-Q system (conductivity $\left.\leq 0.1 \mu \mathrm{S} \cdot \mathrm{cm}^{-1}\right)$.

All experiments, beginning with extraction, were performed under dim light as far as possible and inside vessels and equipment covered with aluminum foil or black cloth, preventing pigments exposure to light (Hynninen 1991). QCT (Sigma Aldrich) was prepared as $20 \mathrm{mM}$ stock solution in dimethyl sulfoxide (DMSO).

\section{Chlorophyll extraction}

Chlorophylls were isolated from plant pigments (extracted from spinach leaves, Spinacia oleracea L.) by using already published method (Svec 1978; Petrović et al. 2006). Fresh spinach leaves were first depleted from the mid ribs and washed with cold water. The extraction and re-extraction mixtures were methanol and petroleum ether in a $2: 1(\mathrm{v} / \mathrm{v})$ ratio, and petroleum ether and diethyl ether $(1: 1, \mathrm{v} / \mathrm{v})$, respectively. The methanol removes water from the plant material and the petroleum ether picks up the pigments before they undergo secondary reactions. The diethyl ether increases pigments solubility in the organic phase. The final extract was a mixture of pigments containing large amounts of various chlorophyll forms (with a predominant contribution of Chla), as well as accessory pigments, carotenoids (carotenes and xanthophylls).

Chlorophyll fraction (Chla with $4 \%$ traces of Chlb) was isolated by column chromatography with silica gel as the adsorbent (silica gel 60, Merck, 0.063-0.200 mm) and $n$-hexane/acetone mixture as the eluent (Zvezdanović et al. 2009). The $n$-hexane/acetone ratio was changed from initial 1:0 to final 1:1 (v/v), to permit an easier elution of the polar fractions. Chlorophyll fraction was eluted at eluent composition 1:0.1 ( $n$-hexane/acetone, $\mathrm{v} / \mathrm{v}$, respectively).

\section{Chlorophyllide extraction}

Chlorophyllides were obtained by the action of the endogenous chlorophyllase on chlorophylls, by incubating $5 \mathrm{~g}$ of dehydrated spinach with $100 \mathrm{ml}$ acetone $/ 0.2 \mathrm{M}$ Tris- $\mathrm{HCl}$ buffer $(\mathrm{pH} 8.0,1: 1, \mathrm{v} / \mathrm{v})$ at $40^{\circ} \mathrm{C}$ for $2 \mathrm{~h}$ in the dark (Hortensteiner et al. 1995).

Chlorophyllide fraction (containing $62.2 \%$ of Chlid $a$, and $24.2 \%$ of Chlid $b$ ) was isolated by column chromatography with silica gel as the adsorbent (silica gel 60, Merck, 0.063$0.200 \mathrm{~mm}$ ) and $n$-hexane/acetone mixture as the eluent. The $n$-hexane/acetone ratio was changed from initial 1:0 to final $0.1: 1(\mathrm{v} / \mathrm{v})$, to permit an easier elution of the polar fractions. Chlorophyllide fraction was eluted at eluent composition 0.3:1 ( $n$-hexane/acetone, v/v, respectively).

The purity of the collected chlorophyll and chlorophyllide samples was monitored by HPLC analysis under isocratic conditions; apparatus: Agilent 1100 Series, Waldborn, Germany; column: Zorbax Eclipse XDB-C18; mobile phase: acetonitrile/ methanol/ethyl acetate, $60: 20: 20$; flow rate: $0.5 \mathrm{~cm}^{3} \cdot \mathrm{min}^{-1}$ at $25^{\circ} \mathrm{C}$. The monitoring wavelength was $430 \mathrm{~nm}$.

\section{Liposomes preparation}

MLV and SUV with pigments inserted in the lipid bilayer were prepared according to the thin-film hydration method, as previously described (Bărbîntă-Pătrascu et al. 2008, 2010). The lipid DPPC was dissolved in chloroform together with the pigment: Chla or Chlid $a$ (molar ratio of Chl $a$ or Chlid $a /$ lipid $=1 / 100)$. The pigment (Chla or Chlid $a$ ) concentration was 5 $\times 10^{-6} \mathrm{M}$, while lipid concentration was $5 \times 10^{-4} \mathrm{M}$, considering the final buffer volume of liposome suspension. Spectral criteria in UV-VIS range of absorption developed for Chla liposomes (Bărbîntă-Pătrascu et al. 2008) were used to rapidly estimate the dimension and unilamellarity of liposomes. All the operations have been performed above the critical temperature $\left(\mathrm{T}_{\mathrm{c}}\right)$ of DPPC $\left(\sim 42^{\circ} \mathrm{C}\right)$ in order to avoid defects. The SUV suspensions were centrifuged 30 minutes, 20000 $\times g$ using SIGMA 2-16 K centrifuge, in order to remove the titanium traces and to obtain homogeneous vesicle populations. Only the supernatants were used in investigations and kept at $4^{\circ} \mathrm{C}$, for several days. Prior spectral measurments, the SUV suspensions were sonicated for several minutes.

\section{QCT experiments}

Aliquots of QCT stock DMSO solution have been added in the cuvette containing the SUV suspension in order to obtain the desired QCT concentration within the range of $0 \div 100 \mu \mathrm{M}$, for the respective spectral measurement. The DMSO concentration ( $/ \mathrm{v})$ in the cuvette did not exceed $0.5 \%$ and control tests revealed that DMSO doesn't influence the fluorescence results. All the QCT 
experiments have been done at $45^{\circ} \mathrm{C}$, temperature above the $\mathrm{T}_{\mathrm{c}}$ of DPPC.

\section{Spectral measurements}

The optical absorption spectra were obtained on a double beam UV-VIS spectrophotometer Lambda 2S Perkin Elmer; the instrument resolution is $1 \mathrm{~nm}$. Steady state fluorescence experiments and fluorescence polarization measurements were performed using a Perkin Elmer LS 55 fluorescence spectrometer fitted with a biokinetic accessory providing continuous monitoring of the temperature in the cuvette and stirring the liposome suspension. The LS 55 fluorescence spectrometer was equipped with R928 photomultiplier, redsensitive photomultiplier fitted for collection of emission data above $630 \mathrm{~nm}$. For the wavelength range 630-750 nm, the corection for emission was not necessary - as proved with fluorescent standards. The instrument is providing automatic correction for excitation. Slits of $5 \mathrm{~nm}$ were used both for excitation and emission. Wavelength accuracy of the instrument is $\pm 1.0 \mathrm{~nm}$ and wavelength reproducibility is $\pm 0.5 \mathrm{~nm}$. An ultra thermostat/circulator Julabo ED 5 with accuracy of $\pm 0.3 \mathrm{~K}$ ensured the constant temperature in the cuvette, during all fluorescence measurements.

The instrument is equipped with polarizers for both excitation and emission beams and the anisotropy or polarization can be measured. In all our experiments, the anisotropy was measured, at specified temperature. The anisotropy is defined as:

$$
r=\frac{I_{V V}-G I_{V H}}{I_{V V}+2 G I_{V H}}
$$

A

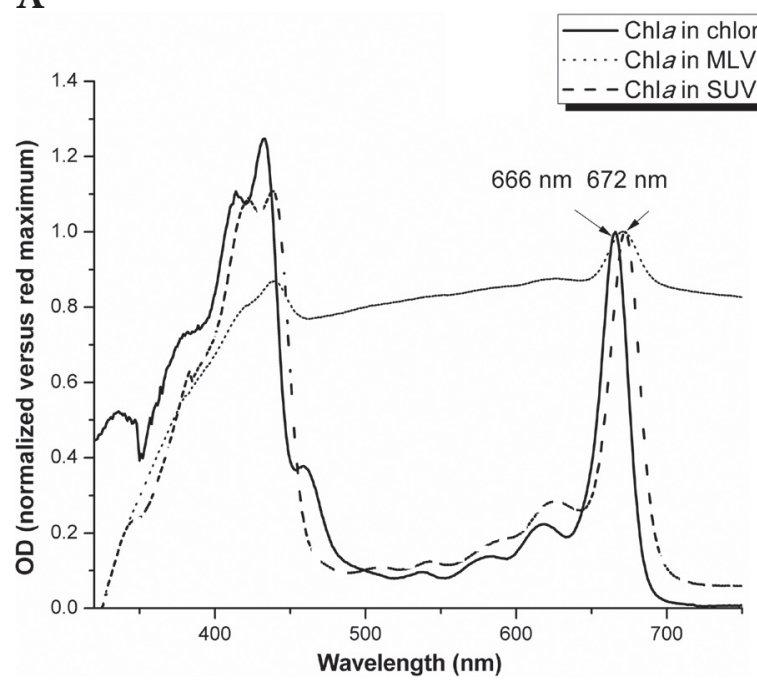

where: $I_{V V}$ is the relative intensity when both excitation and emission beams are vertically polarized, $I_{V H}$ is the relative intensity when excitation is vertically polarized and emission is horizontally polarized, $G$ represents the ratio of the sensitivities of the detection system for vertically and horizontally polarized light.

For every measurement (specified wavelengths for excitation and emission) a prior experiment was done, for $\mathrm{G}$ factor determination. The $\mathrm{G}$ factor and the anisotropy are automatically calculated by using the instrument software.

All spectral data have been processed by using the software Origin 8.0.

\section{Results}

UV-VIS absorption spectra of liposomes (SUV, MLV) incorporating Chla or Chlid $a$ are presented in Figure 2. The spectrum of the corresponding pigment in solution (in chloroform, at a concentration of $10^{-6} \mathrm{M}$ ) is jointly presented.

The liposomes scatter light and the absorption spectra are affected (the baseline is shifted and presents wavelength dependence). The light scattering presented by larger vesicles (MLV) suspensions differs from that of the small vesicles (SUV). Assuming a Rayleigh scattering in the case of both types of liposome suspensions, the over-estimated absorbance values were corrected for the contribution of light scattering on the basis of the O.D. measured at $325 \mathrm{~nm}$, where the scattering is the major contributor to the O.D. (Bittner et al. 2002). The correction worked well for SUV, small particles, but did not correct the baseline in the case of MLV. The Rayleigh scattering applies for particles with radius (R)
B

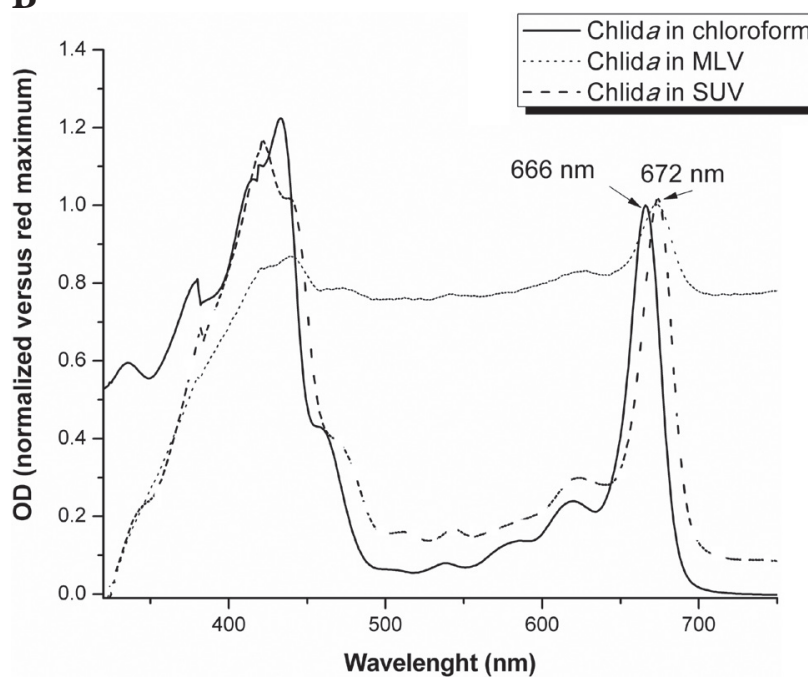

Figure 2. VIS absorption of Chla (A) and Chlid $a(\mathbf{B})$ in chloroform solution $\left(10^{-6} \mathrm{M}\right.$ concentration) and incorporated in DPPC liposomes (pigment/lipid =1/100). The spectra of pigments incorporated in liposomes are corrected for Rayleigh scattering. All the spectra are normalized versus the red maximum. 
A

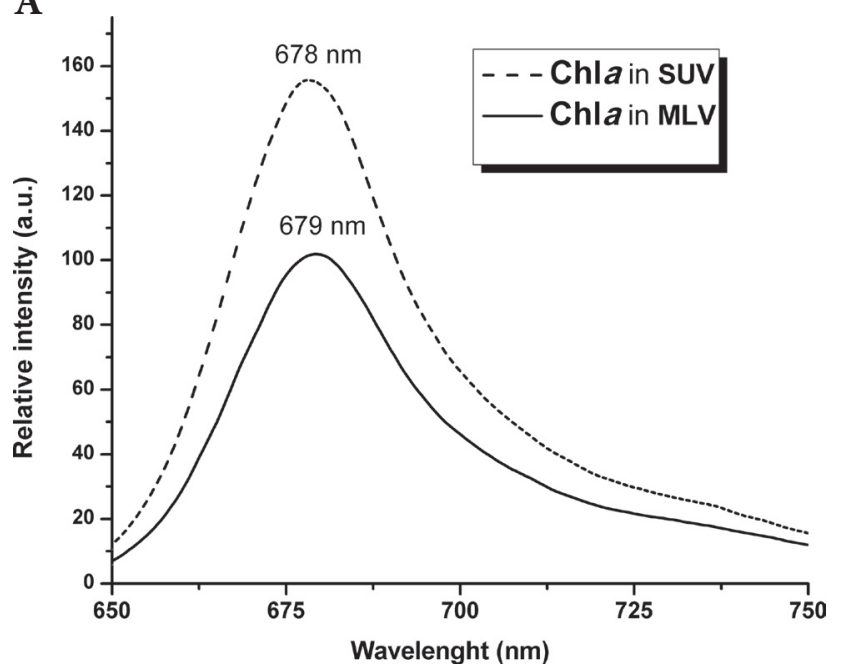

B

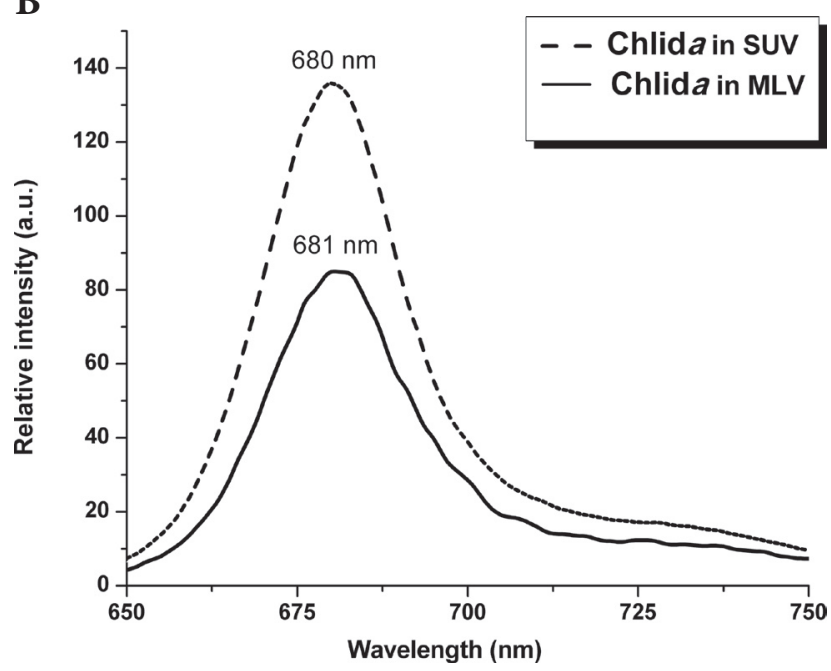

Figure 3. Emission spectra of Chla (A) and Chlid $a(\mathbf{B})$, incorporated in DPPC liposomes (MLV and SUV) obtained with the excitation beam of $430 \mathrm{~nm}\left(\lambda_{\text {exc }}=430 \mathrm{~nm}\right)$.

shorter than $\lambda / 20(\mathrm{R}<\lambda / 20)$ and this ,rule” provides a rapid estimation of the liposomes dimension by inspecting the corrected spectra (Bărbînță-Pătraşcu et al. 2010). All O.D. were normalized versus the red maximum in the respective absorption spectra. The spectra of Chla and Chlid $a$ in SUV and in chloroform solution are similar as regarding the shape and peak positions. The difference, observed especially in the case of MLV spectra, is a consequence of the light scattering, other than Rayleigh scattering, and possible reflections present in different extent.

Fluorescence emission spectra of liposomes (SUV, MLV) with Chlid $a$, compared with the spectra of liposomes with $\mathrm{Chl} a$, are presented in Figure 3.

A

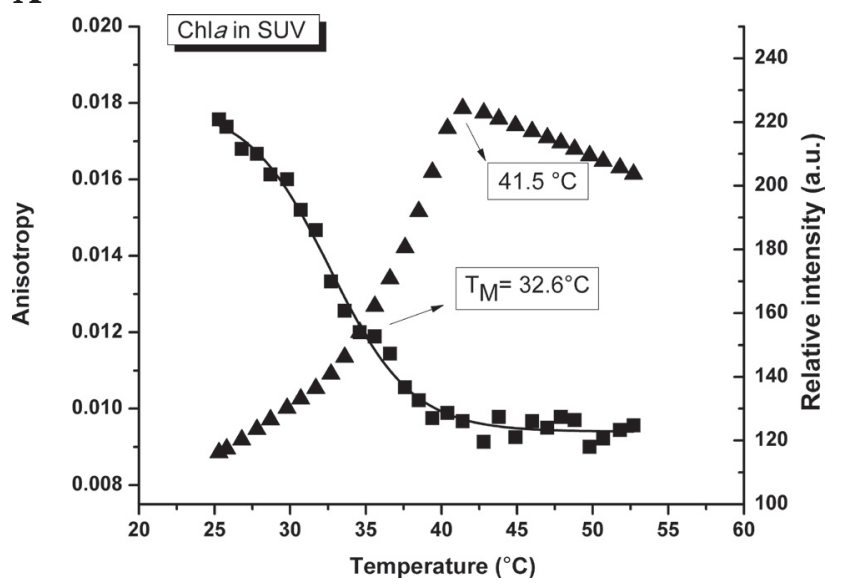

Chla and Chlid $a$ fluorescence emission in liposomes suspensions was measured in steady-state conditions. The longest wavelength maximum in the Soret band was used as the excitation wavelength for all emission spectra. Chla and Chlid $a$ were used as fluorescent probes and molecular sensors in all the fluorescence experiments on liposome suspensions. The peak emission of Chla incorporated in liposomes is red shifted as compared with the maximum position $(675 \mathrm{~nm})$ in chloroform, at a concentration of $10^{-6} \mathrm{M}$ (Bărbînță-Pătraşcu et al. 2010).

The temperature dependence of both anisotropy and relative intensity of the fluorescence of Chla and Chlid $a$ in SUVs are represented in Figure 4. The (fluorescence)

B

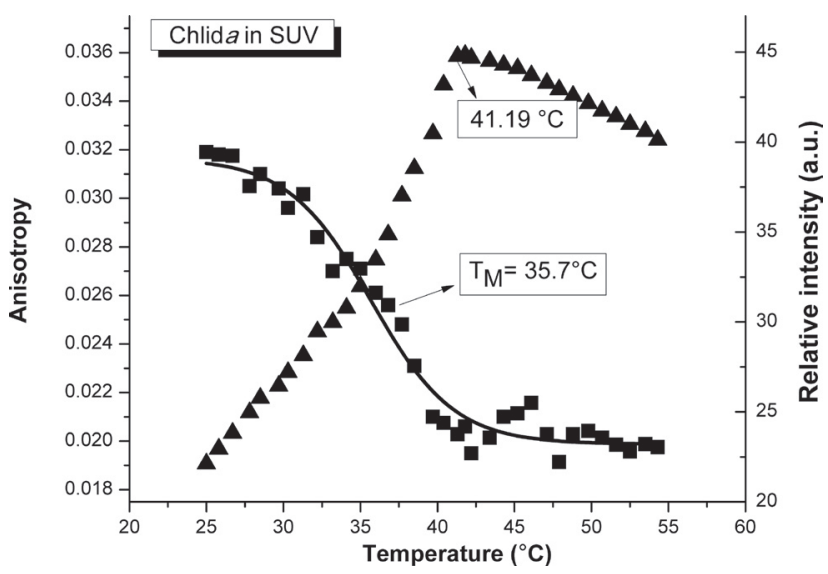

Figure 4. Phase transitions monitored by the variation of fluorescence emission (relative intensity - $\mathbf{\nabla}$ ) and emission anisotropy (anisotropy --) of Chla (A) and Chlida (B) in DPPC-SUVs. $\mathrm{T}_{\mathrm{m}}$ is the center value of the fit curve using the Boltzmann function. 
A

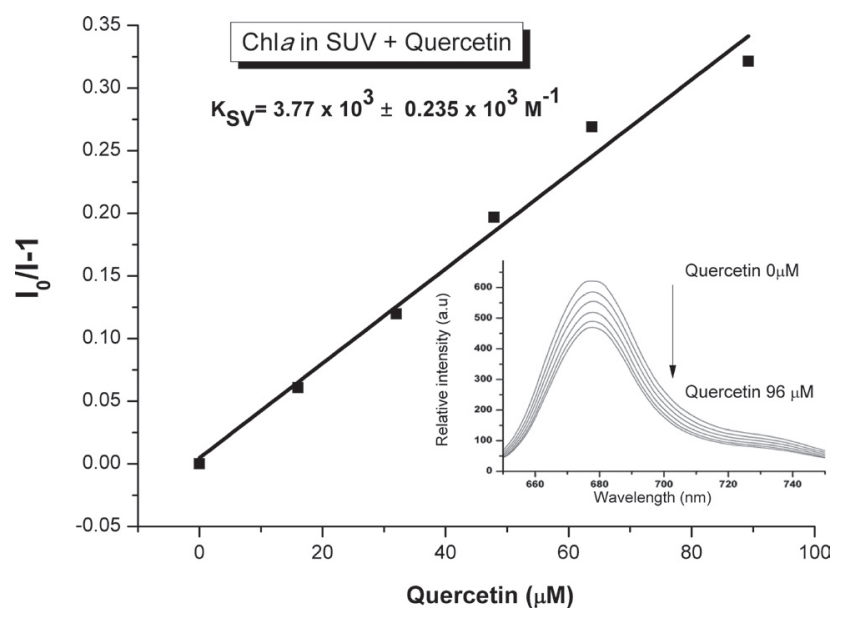

B

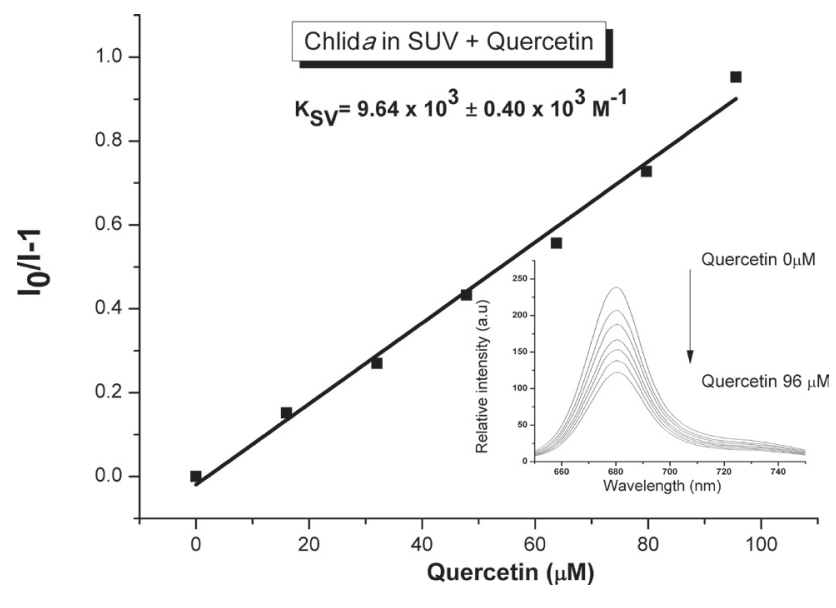

Figure 5. Stern-Volmer plots for Chla (A) and Chlid $a(\mathbf{B})$ incorporated in SUV liposomes, QCT acting as quencher. The fluorescence of Chla or Chlid $a$ as a function of the quencher (QCT) concentration is shown in the inset $\left(\mathrm{T}=45^{\circ} \mathrm{C}\right) . I_{0}$ and $I$ are the steady-state fluorescence intensities in the absence and presence of quencher, respectively; $\mathrm{K}_{\mathrm{SV}}=\mathrm{K}_{\mathrm{q}} \tau_{0}$ is the Stern-Volmer constant.

emission anisotropy values and relative intensities for Chla in liposomes were recorded at $\lambda_{\mathrm{em}}=678 \mathrm{~nm}$ by using the excitation beam of $430 \mathrm{~nm}\left(\lambda_{\text {exc }}=430 \mathrm{~nm}\right)$. The corresponding values for Chlid $a$ in liposomes are: $\lambda_{\mathrm{em}}=680 \mathrm{~nm}$ and $\lambda_{\text {exc }}=436 \mathrm{~nm}$. For each measurement, the correction for $\mathrm{G}$ factor was applied.

Chla fluorescence emission in liposomes suspensions was measured in the presence of QCT, added in the concentration range $0-100 \mu \mathrm{M}$. The addition of the QCT leads to a quenching effect of the pigment fluorescence (insets in Figure 5). In both cases, a linear relationship has been

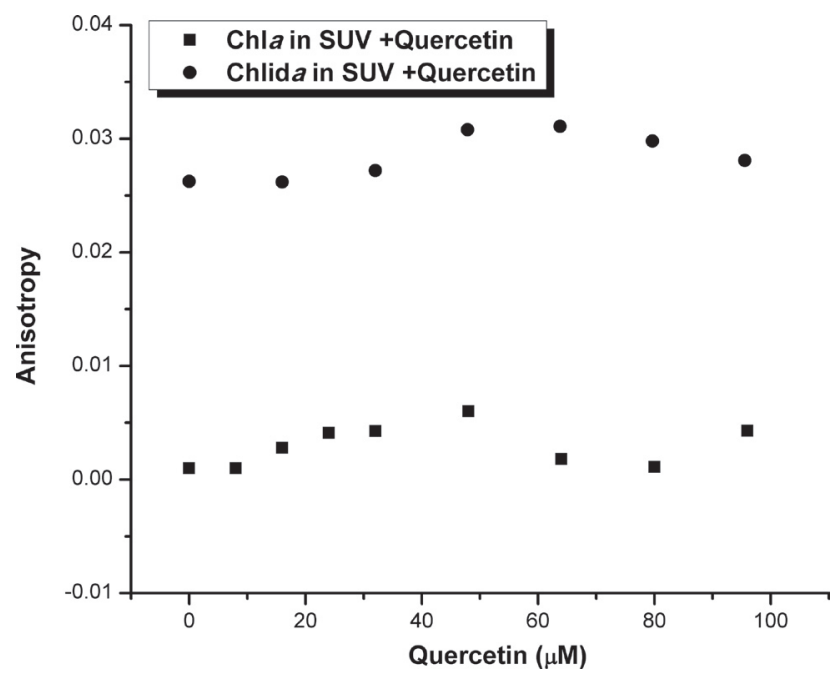

Figure 6. The dependence of emission anisotropy upon QCT concentration for Chla and Chlid $a$ SUVs $\left(\mathrm{T}=45^{\circ} \mathrm{C}\right)$. obtained by plotting the relative intensity ratio versus the QCT concentration (Figure 5).

QCT quenching of Chla or Chlid $a$ fluorescence respects the Stern-Volmer equation (Lakowicz 1983):

$$
I_{0} / I=1+\mathrm{K}_{\mathrm{q}} \tau_{0}[Q]=1+\mathrm{K}_{\mathrm{SV}}[Q]
$$

where: $I_{0}$ and $I$ are the steady-state fluorescence intensities in the absence and presence of quencher, respectively; $\mathrm{K}_{\mathrm{SV}}=\mathrm{K}_{\mathrm{q}} \tau_{0}$ is the Stern-Volmer constant; $\tau_{0}$ is the fluorescence lifetime in the absence of the QCT; [Q] is the quencher (QCT) concentration; $\mathrm{K}_{\mathrm{q}}$ is the bimolecular quenching constant.

The addition of QCT in both types of liposomes (DPPC SUV with Chla or Chlid $a$ incorporated) resulted in a slight increase of the emission anisotropy values only in the concentration range: $0-50 \mu \mathrm{M}$ (Figure 6). The emission anisotopy values were recorded at $45^{\circ} \mathrm{C}$, therefore the lipid (DPPC) was in the liquid crystal phase.

\section{Discussion}

The main absorption bands of Chla and Chlid $a$ (Soret band and red band) are present in all the spectra from Fig. 2. The red band $\left(\mathrm{Q}_{\mathrm{y}}\right)$ of both pigments incorporated in liposomes (SUV and MLV) is shifted to longer wavelengths as comparing with Chla or Chlida spectrum in chloroform solution. It is likely to consider that the red shift of the pigment red maximum in liposomes is due to the polar environment in which the porphyrin macrocycle is located - the lipid-water interface in the vicinity of polar lipid heads, rather than to 
the presence of the pigments in aggregated forms (dimers). The concentration of pigments in liposomes is low (approximately $10^{-6} \mathrm{M}$ ) and usually at this concentration, the monomeric form is dominant, even in non-polar solvents (Zvezdanović et al. 2009). The comparison with the red band position of Chla, recorded in a native, highly-organized structure of pigment-protein complexes of isolated thylakoids - where Chls exist in aggregated form with the maximum at $679 \mathrm{~nm}$ (Santabarbara 2006) - is pleading also for the existence of pigments mainly in monomeric form in the lipid bilayers of liposomes.

Chl $a$ and Chlid $a$ incorporated in liposomes present fluorescence emission maxima (Fig. 3) at longer wavelength as comparing with the fluorescence emission in chloroform. The red shifts (4-6 nm) could be explained by a more polar environment sensed by the fluorophore. The fluorophore, in the case of Chl $a$ and Chlid $a$, is represented by the porphyrin macrocycle. In the liposome lipid bilayer, Chla is located with the macrocycle at the interface with the water phase in the vicinity of the lipid polar heads, and the phytyl tail in the hydrophobic lipid chains region (Țugulea and Paşcanu 1996). The red shift is slightly larger in the case of Chlida, suggesting that Chlid $a$ better senses the polar region of the lipid bilayer than Chla, which penetrates more deeply into the lipid layer. The hydrophobic phytyl chain of Chla is responsible for the penetration of Chla into the hydrophobic core of the lipid bilayer.

The Chla incorporated in the liposomal membrane exhibited a lower degree of emission anisotropy as compared with that obtained in the case of Chlid $a$ (Fig. 4). This fact suggests also that the Chla fluorophore senses a more flexible microenvironment, as compared with Chlid $a$. Chlid $a$ macrocycle, preferentially localized in the vicinity of the lipid polar heads, senses a more rigid microenvironment (lipid heads) as compared with the lipid tails region in the bilayer.

The temperature dependence of the emission anisotropy of pigments (Chl $a$ and Chlid $a$ ) incorporated in DPPC bilayers covers three regions:

- a region with high values of the emission anisotropy, in the temperature range below $28^{\circ} \mathrm{C}$. In this temperatures range, the DPPC bilayers are in a gel phase, compact and rigid molecular organisation

- a region with decreasing values of emission anisotropy, in the temperature range $28-40^{\circ} \mathrm{C}$. In this temperature range, the pigments sense lipids in both phases: gel and liquid crystal. The behaviour, in both cases, is pleading for a cooperativity in transition from one phase to another. The midpoint of the Boltzmann fit is represented in both graphs; the values are obviously quite similar because both pigments sense the transition of the same lipid: DPPC

- a region with lower values of the emission anisotropy, starting at the temperature higher than $41^{\circ} \mathrm{C}$. The tran- sition temperature of DPPC (as indicated by Sigma Aldrich, the supplying company) is within the interval $41-42^{\circ} \mathrm{C}$.

The temperature increase, in the investigated range, did not induce fusion of the small vesicles (Chla-SUV or Chlid $a$-SUV), as it was proved by the absence of changes in the control absorption spectra of SUV suspensions.

The plots of the relative emission intensities upon temperature present a similar behaviour, no matter which pigment senses the phase transition (Fig. 4). The increase of the pigment fluorescence in the temperature range $28-41^{\circ} \mathrm{C}$ can be explained by the diminuation of the fluorescence quenching: the fluorophores will change more easily their relative position in a more flexible environment and as a consequence, the quenching by a mechanism of energy transfer is less efficient. The pigments concentration was not high enough to explain a quenching due to the presence of non-fluorescent aggregated forms of pigments. A more rigid microenvironment can contribute to an effective transfer (Förster resonant energy transfer) among Chlal Chlid $a$ molecules, respectively. The slow decrease of the fluorescence after the transition temperature $\left(41-42^{\circ} \mathrm{C}\right)$ indicates a new arrangement of the pigments facing the new phase of the lipid bilayer.

\section{QCT effects on liposome lipid bilayers}

A linear Stern-Volmer plot is generally indicative of a single class of fluorophores, all equally accessible to quencher and can be obtained either in the case of dynamic or static quenching (Lakowicz 1983). It is obvious that in the present case, the Chla and Chlid $a$ fluorescence quenching by QCT (Fig. 5), the linear Stern-Volmer plots are pleading for one single class of fluorophore (porphyrin ring) accessible to the quencher (QCT).

The calculated Stern-Volmer constants differ in the case of the two pigments incorporated in SUV. Considering a value of $4.9 \mathrm{~ns}$ for $\tau_{0}$ (Picard et al. 1986), for both Chl $a$ and Chlid $a$ in SUV, the bimolecular quenching constants $\mathrm{K}_{\mathrm{q}}\left(\mathrm{K}_{\mathrm{SV}} / \tau_{0}\right)$ were calculated and listed below:

$$
\begin{aligned}
& \text { SUV-Chla: } \mathrm{K}_{\mathrm{q}}=7.7 \times 10^{11} \mathrm{M}^{-1} \cdot \mathrm{s}^{-1} \\
& \text { SUV-Chlid } a: \mathrm{K}_{\mathrm{q}}=1.97 \times 10^{12} \mathrm{M}^{-1} \cdot \mathrm{s}^{-1}
\end{aligned}
$$

The bimolecular quenching constants are higher for Chlid $a$ as compared to Chla . Both $\mathrm{K}_{\mathrm{q}}$ values are close to the value reported for porphyrins freely dissolved in aqueous solutions: $\mathrm{K}_{\mathrm{q}}=(2.3-2.6) \times 10^{11} \mathrm{M}^{-1} \cdot \mathrm{s}^{-1}$ (Ricchelli 1991). This fact suggests that the pigments accessible to the quencher can be considered as being localized in regions of the outer lipid monolayer, exposed to the solvent. A dynamic quenching (collisional process) is characterized by bimolecular quenching constants in the range of $10^{9}-10^{10} \mathrm{M}^{-1} \cdot \mathrm{s}^{-1}$. Therefore, 
a static process could be rather considered as responsible for Chla and especially for Chlid $a$ quenching by QCT. In some cases a complex formation in the ground state could be responsible for the quenching process (Valeur 2001). In the absence of the appropriate evidence (e.g. changes in the absorption spectrum upon complexation), the interaction is likely to be non-specific and the model of an effective sphere of quenching is more appropriate (Valeur 2001). Neither changes of the absorption spectra or emission spectra (except variations of the relative intensity) have been observed in the case of liposomes with Chla or Chlid $a$ upon addition of QCT. An effective sphere of quenching of Chla and Chlid $a$ fluorescence could be assumed as fitting the obtained results. Chlid $a$ and QCT could be considered as competitive for the same places of insertion in the outer monolayer of the liposomal bilayer.

The addition of QCT in both types of liposomes (DPPC SUV with Chla or Chlid $a$ incorporated) resulted in a slight increase of the emission anisotropy values in the concentration range: $0-50 \mu \mathrm{M}$. QCT has access only to the pigments inserted in the outer lipid monolayer of liposomes (SUV) and, as revealed by quenching experiments, is in competition with the pigments, especially with Chlid $a$, for the insertion places in the vicinity of lipid polar heads. The value of $\sim 50 \mu \mathrm{M}$ seems to be critical for the QCT effects on lipid bilayers in SUV no matter of lipid nature since similar results were obtained with DMPC SUV (Drăguşin et al. 2010). Probably, the curvature of the small liposomes is limiting the insertion of QCT at a certain concentration.

VIS absorption spectra of Chla and Chlid $a$ (Soret band and red $\mathrm{Q}_{\mathrm{y}}$ band) confirm the localization of the porphyrin macrocycle of Chla and Chlid $a$ at the lipid-water interface in the vicinity of polar lipid heads. Fluorescence spectra also confirm localization of Chla and Chlid $a$ in the vicinity of lipid polar heads, but the red shift of the $\left(\mathrm{Q}_{\mathrm{y}}\right)$ band is more expressed for Chlid $a$ than for Chla, because Chlid $a$ stronger senses the polar environment of the lipid heads. The temperature dependence of emission anisotropy for Chla and Chlid $a$, incorporated in DPPC SUVs, revealed the presence of three different phases in the investigated region (a large range around $\mathrm{T}_{\mathrm{c}}$ of DPPC). Lower fluorescence anisotropy values have been obtained for Chla-SUVs as compared to Chlida-SUVs. Because of the phytyl chain, penetrating the hydrophobic fatty acid region of the lipid bilayer, Chla is sensing a more flexible micro-environment as compared with Chlid $a$, which senses only the lipid polar head region of the bilayer.

The pigments fluorescence quenching by QCT is a rather static process. The higher Stern Volmer constant $\left(\mathrm{K}_{\mathrm{sV}}\right)$, obtained in the case of Chlida SUVs as compared to Chla SUVs, provides arguments for the insertion of QCT at the interface lipid/water in the lipid bilayer, in the vecinity of lipid polar heads.
Both Chla and Chlid $a$ proved to be excellent molecular sensors for the lipid bilayers of the DPPC liposomes prepared with the incorporated pigments.

Acknowledgment. This work was supported under the projects number TR-34012 and OI-172044, by the Ministry of Education and Science of The Republic of Serbia; strategic grants: POSDRU/89/1.5/S/58852 „Postdoctoral programme for training scientific researchers" (M.B-P.) and POSDRU/107/1.5/S/80765 „Excellency and Interdisciplinarity in doctoral studies for an informational society" (G. B.), co-financed from the ESF within the Sectorial Operational Program Human Resources Development 2007-2013.

\section{References}

Almela L., Fernández-López J. A., Roca M. J. (2000): High-performance liquid chromatographic screening of chlorophyll derivatives produced during fruit storage. J. Chromatogr. A 870, 483-489

http://dx.doi.org/10.1016/S0021-9673(99)00999-1

Bărbînță-Pătraşcu M. E., Țugulea L., Meghea A., Popescu A. (2008): Oxidative stress on liposomes with chlorophyll a monitored by spectral studies. OAM-RC 2, 113-116

Bărbînță-Pătraşcu M. E., Țugulea L., Lăcătuşu I., Meghea A. (2010): Spectroscopic characterization of model systems with lipids and Chlorophyll. Mol. Cryst. Liq. Cryst. 522, 148-158

Bittner O., Gal S., Pinchuk I., Danino D., Shinar H., Lichtenberg D. (2002): Copper-induced peroxidation of liposomal palmitoyllinoleoylphosphatidylcholine (PLPC), effect of antioxidants and its dependence on the oxidative stress. Chem. Phys. Lipids 114, 81-98 http://dx.doi.org/10.1016/S0009-3084(01)00208-0

Brandis A. S., Salomon Y., Scherz A. (2006a): Chlorophyll sensitizers in photodynamic therapy. In: Chlorophylls and Bacteriophylls: Biochemistry, Biophysics, Functions and Applications. Advances in Photosynthesis and Respiration. Vol. 25 (Eds. B. Grimm, R. J. Porra, W. Rudiger and H. Scheer), pp. 461-483, Springer, Dordrecht, Netherlands

Brandis A. S., Salomon Y., Scherz A. (2006b): Bacteriochlorophyll sensitizers in photodynamic therapy. In: Chlorophylls and Bacteriophylls: Biochemistry, Biophysics, Functions and Applications. Advances in Photosynthesis and Respiration. Vol. 25 (Eds. B. Grimm, R. J. Porra, W. Rudiger and H. Scheer) pp. 485-549, Springer, Dordrecht, Netherlands

Brown S. B., Houghton J. D., Hendry G. A. F. (1991): Chlorophyll breakdown. In: Chlorophylls. (Eds. H. Scheer), pp. 465-489, CRC Presss, Boca Raton, Florida

Cvetković D., Marković D., Cvetković D., Radovanović B. (2011): Effects of continuous UV-irradiation on the antioxidant activities of quercetin and rutin in solution in the presence of lecithin as the protective target. J. Serb. Chem. Soc. 76, 973-985 http://dx.doi.org/10.2298/JSC101123089C

Drăguşin M., Ţugulea L., Ganea C. (2010): The effects of the natural antioxidant quercetin and anions of the Hofmeister series on 
liposomes marked with chlorophyll a. Gen. Physiol. Biophys. 29, 41-49 http://dx.doi.org/10.4149/gpb_2010_01_41

Hortensteiner S., Vicentini F., Matile P. (1995): Chlorophyll breakdown in senescente cotyledons of rape, Brassica napus L. enzymatic cleavage of pheophorbide a in vitro. New Phytol. 129, 237-246 http://dx.doi.org/10.1111/j.1469-8137.1995.tb04293.x

Hynninen P. H. (1991): Chemistry of chlorophylls: Modifications. In: Chlorophylls. (Eds. H. Scheer), pp. 145-209, CRC Presss, Boca Raton, Florida

Jeffrey S. W. (1997): Application of pigment methods to oceanography. In: Phytoplankton Pigments in Oceanography: Guidelines to Modern Methods. (Eds. Jeffrey S. W., Mantoura R. F. C., Wright S. W.), pp. 127-166, UNESCO, Paris

Lakowicz J. R. (1983): Principles of Fluorescence Spectroscopy. Plenum Press, New York http://dx.doi.org/10.1007/978-1-4615-7658-7

Košinova P., Berka K., Wykes M., Otyepka M., Trouillas P. (2012): Positionning of antioxidant quercetin and it's metabolites in lipid bilayer membranes: implication for their lipid-peroxidation inhibition. J. Phys. Chem. B 116, 1309-1318 http://dx.doi.org/10.1021/jp208731g

Markovic D., Proll S., Bubenzer C., Scheer H. (2007): Myoglobin with chlorophyllous chromophores: influence on protein stability. Biochim.Biophys. Acta 1767, 897-904 http://dx.doi.org/10.1016/j.bbabio.2007.03.011

Moser J. G. (1998): Definitions and general properties of 2nd snd 3rd generation photosensitizers. In: Photodinamic tumor therapy 2 nd and 3rd generation photosensitizers. (Ed. J. G. Moser), pp. 3-7, Harwood Academic Publishers, Amsterdam, Netherlands

Müller A. H., Gough S. P., Bollivar D. W., Meldal M., Willows R. D., HanssonM. (2011): Methods for the preparation of chlorophyllide a: An intermediate of the chlorophyll biosynthetic pathway. Anal. Biochem. 419, 271-276 http://dx.doi.org/10.1016/j.ab.2011.08.028

Petrović J., Nikolić G., Marković D. (2006): Im vitro complexes of copper and zinc with chlorophyll. J. Serb. Chem. Soc. 71, 501-512

Picard G., Munger G., Leblanc R. M., Le Sage R., Sharma D., Siemiarczuk A., Bolton J. R. (1986): Fluorescence lifetime of chlorophyll a in pure and mixed langmuir-blodgett films. Chem. Phys. Letters 129, 41-47 http://dx.doi.org/10.1016/0009-2614(86)80165-8

Proll S., Wilhelm B., Robert B., Scheer H. (2006): Myoglobin with modified tetrapyrrole chromophores: binding specificity and photochemistry. Biochim. Biophys. Acta 1757, 750-763 http://dx.doi.org/10.1016/j.bbabio.2006.03.026

Ricchelli F. (1991): Liposomes as models to study distribution of porphyrins in cell membranes. Biochim. Biophys. Acta 1065, $42-48$ http://dx.doi.org/10.1016/0005-2736(91)90008-V

Rosenbach-Belkın V. A. R. D. A., Fiedor L., Salomon Y., Scherz A. (1998): Photodynamic tumor therapy: 2nd and 3rd generation photosensitizers. In: Chlorophyll and Bacteriochlorophyll Derivatıves as Photodynamic Agents. (Ed. J. G. Moser), pp. 117, Harwood Academic Publishers, Amsterdam, Netherlands
Rudiger W. (2006): Biosynthesis of chlorophylls a and b: the last steps. In: Chlorophylls and Bacteriophylls. Biochemistry, Biophysics, Functions and Applications. Advances in Photosynthesis and Respiration. Vol. 25 (Eds. B. Grimm, R. J. Porra, W. Rudiger, H. Scheer), pp. 189-200, Springer, Dordrecht, Netherlands

Santabarbara S. (2006): Limited sensitivity of pigment photo-oxidation in isolated thylakoids to singlet excited state quenching in photosystem II antenna. Arch. Biochem. Biophys. 455, 77-88 http://dx.doi.org/10.1016/j.abb.2006.08.017

Scheer H. (2006): An overview of chlorophylls and bactoriophylls: biochemistry, biophysics, functions and applications. In: Chlorophylls and Bacteriophylls. Biochemistry, Biophysics, Functions and Applications. Advances in Photosynthesis and Respiration. Vol. 25 (Eds. B. Grimm, R. J. Porra, W. Rudiger, H. Scheer), pp. 1-26, Springer, Dordrecht, Netherlands

Scheer H. (2003a): The pigments. In: Light Harvesting Antennas in Photosynthesis. (Eds. B. R. Green, W. W. Parson), pp. 29-81, Kluwer Academic Publishers, Netherlands http://dx.doi.org/10.1007/978-94-017-2087-8_2

Scheer H. (2003b): Chemistry and spectroscopy of chlorophylls. In: CRC Handbook of Organic Photochemistry and Photobiology. (Eds. W. Horspool, F. Lenci), pp. 117, CRC Press, Boca Raton, Florida

Schlichter J., Friedrich J., Parbel M., Scheer H. (2000): New concepts in spectral diffusion physics of proteins. Photon Sci. News 6, $100-110$

Svec W. A. (1978): Isolation, preparation and characterization and estimation of thechlorophylls and bacteriochlorophylls. In: The Porphyrins. (Eds. D. Dolphyn), pp. 341-399, Academic press, New York

Țugulea L., Paşcanu S. (1996): Chlorophyll a - molecular sensor in model lipid membranes. Rom. J. Biophys. 6, 1-10

Valeur B. (2001): Molecular Fluorescence: Principles and Applications. Wiley-VCH Verlag, GmbH, Weinheim, pp. 72-125 http://dx.doi.org/10.1002/3527600248.ch4

Yasuyo S., Yuzo S. (2003): Identification of chlorophylls and carotenoids in major teas by high-performance liquid chromatography with photodiode array detection. J. Agric. Food Chem. 51, 5307-5314 http://dx.doi.org/10.1021/jf030158d

Yuzo S., Kenji W., Kenichiro T. (1996): Enzymatic conversion of pheophorbide a to the precursor of pyropheophorbide a in leaves of chenopodium album. Plant Cell Physiol. 37, 1143-1149

Zvezdanović J., Cvetić T., Veljović- Jovanović S., Marković D. (2009): Chlorophyll bleaching by UV-irradiation in vitro and in situ: Absorption and fluorescence studies. Radiation Phys. Chem. 78, 25-32 http://dx.doi.org/10.1016/j.radphyschem.2008.07.006

Zvezdanović J. B., Marković D. Z., Cvetković D. J., Stanojević J. S. (2012): UV-induced change in quercetin antioxidant activity toward benzophenone initiated lipid peroxidation. J. Serb. Chem. Soc. 77, 1571-1588 http://dx.doi.org/10.2298/JSC120012059Z

Received: February 1, 2013

Final version accepted: May 22, 2013 